\title{
O Desempenho dos Países que Adotaram o Regime de Metas Inflacionárias: uma Análise Comparativa
}

\author{
Roberta Loboda Biondi * \\ Rudinei Toneto Jr. **
}

Resumo: $O$ objetivo desse trabalho é analisar qualitativamente o desempenho de países que adotaram o regime de metas de inflação. A comparação foi realizada entre os países que adotam o regime de metas inflacionárias e os países que não adotam a partir de estatísticas descritivas como a volatilidade das taxas de inflação e crescimento real do produto. Países desenvolvidos e em desenvolvimento foram separados em grupos e posteriormente foi realizada uma comparação entre tais países a fim de diferenciar o desempenho dos dois grupos quando da adoção do sistema de metas de inflação. Os resultados encontrados foram que países que adotam o regime de metas inflacionárias experimentam uma menor volatilidade das taxas de inflação e menores taxas médias de crescimento real do produto. Para os países em desenvolvimento, os custos de convergência da taxa de inflação para a meta são ainda maiores em termos de baixo crescimento do produto.

Palavras-chave: Metas de Inflação, Taxas de Crescimento do Produto, Países Desenvolvidos, Países em Desenvolvimento.

Abstract: This work's purpose is to analyze, qualitatively, the performance of countries that have taken inflation targeting principles. The comparison was made among countries that do not make use of such method and those that do so, based on descriptive statistics, such as the volatility of inflation rates and real GDP growth. Aiming to confront and analyze the performance of developed and developing countries that make use of inflation targeting, they were separated into groups. The results show that countries with inflation targeting purposes present a lower volatility of inflation rates and also lower mean real GDP growth rates. Speaking of developing countries, the costs inferred in inflation rate convergence to the target are even higher when a lower GDP growth is approached.

Keywords: Inflation Targeting, GDP Growth Rates, Developed Countries, Developing Countries.

\footnotetext{
"Economista, Professora do Departamento de Economia da FEA-RP/USP, Mestranda do Programa de Economia Aplicada - FEA-RP/USP. E-mail: rloboda@fearp.usp.br

" Professor Associado do Departamento de Economia da FEA-RP/USP. E-mail: rtoneto@usp.br. Recebido em 08/09/05 e aceito em 15/12/05.
} 


\section{Introdução}

Desde de 1999 o Brasil baseia sua política macroeconômica no tripé considerado o mais consistente, ou o mais moderno, por acadêmicos, policy makers e organismos internacionais: câmbio flutuante, superávit primário (equilíbrio fiscal) e metas de inflação.

Alega-se que a primeira peça do tripé é necessária para garantir o ajustamento do balanço de pagamentos, a segunda é necessária ao controle da demanda e para evitar amplas flutuaçóes cambiais além de permitir a liberação da taxa de juros para fins de controle inflacionário e a terceira é utilizada como a âncora (referência) nominal do sistema.

A necessidade de uma referência nominal decorre da visão de "neutralidade da moeda”, assim como dos custos de transação e decisóes envolvidas em contextos de ampla variabilidade de preços. Tais custos associados à presença da inflação na economia, a sua volatilidade e os erros de decisóes dos indivíduos em função deste aspecto, poderiam levar a menores taxas de crescimento no longo prazo ${ }^{1}$.

Assim, de acordo com essa concepção, dada à neutralidade da moeda, somadas as possibilidades de ineficiências associadas a decisóes equivocadas, coloca-se a necessidade de âncoras nominais, para as quais existem três principais tipos: âncora cambial, âncora monetária ou metas de inflação.

Esse último regime tem sido adotado em vários países industrializados e em desenvolvimento nos últimos anos, desde sua adoção pioneira na Nova Zelândia em 1990, seguida por Canadá e Chile (1991), Reino Unido (1992) e Suécia (1993).

Nos últimos anos foram realizados vários estudos com o objetivo de detectar a eficiência do regime de metas inflacionárias em reduzir a variabilidade das taxas de inflação e em relação às conseqüências dessa estratégia de política monetária para o desempenho do produto. Alguns desses estudos não se mostraram conclusivos em relação ao impacto da adoção do regime de metas no desempenho da atividade econômica do país como descrito em Arestis e Sawyer (2003). Já no estudo realizado por Mishkin (2000), o autor destaca que no contexto das estratégias de política monetária, o regime de metas inflacionárias é dotado de algumas vantagens em relação aos demais regimes como o de metas monetárias e âncora cambial, devido à possibilidade

\footnotetext{
${ }^{1}$ Sobre a relação entre inflação e crescimento econômico ver Barro (1997)
} 
de se tratar com mais veemência as questóes domésticas e garantir maior transparência na política monetária. Mesmo com diferentes resultados encontrados em relação ao desempenho do produto de uma economia sob as diretrizes do regime de metas inflacionárias, há um consenso entre os autores de que tal regime é eficaz em reduzir as taxas de inflação dos países.

Assim como descrito em um estudo de Wu (2004), os países industrializados que oficialmente adotaram o regime de metas de inflação experimentaram uma significativa redução em suas taxas médias de inflação e uma elevação em suas taxas de juros reais. Entretanto, nesse mesmo estudo, há a comprovação de que a redução nas taxas médias de inflação dos países não ocorrera somente em virtude de uma elevaçáo nas taxas reais de juros da economia, ou seja, a política monetária mais agressiva detectada nos países não era a única causa da redução nas taxas médias de inflação. A adoção oficial do regime de metas inflacionárias e o grau de credibilidade do mesmo desempenham um papel importante na eficácia em reduzir as taxas de inflação dos países.

$\mathrm{O}$ regime de metas inflacionárias constitui um ambiente operacional para a política monetária caracterizado pelo anúncio oficial de alvos quantitativos para a taxa de inflaçáo cobrindo um ou mais horizontes de tempo, além do reconhecimento explícito de que a estabilidade de preços é o principal objetivo das autoridades monetárias. Distinto do regime de regras monetárias, o mesmo obriga à existência dos instrumentos de política monetária e a conecção desses com o mecanismo de transmissão monetária, canal através do quê uma mudança na política monetária é capaz de afetar a economia.

$\mathrm{O}$ instrumento de política monetária mais utilizado pelas autoridades monetárias de vários países para atingir a meta de inflação pré-determinada é a taxa de juros segundo a regra e Taylor. Por essa regra a taxa de juros da economia deveria ser elevada quando houvesse inflação e reduzida quando os preços estivessem em queda.

No Brasil, a definição da taxa de juros é de competência do COPOM (Comitê de Política Monetária), e a meta de inflação é determinada pelo Conselho Monetário Nacional (CMN). Desde a adoção do regime de metas inflacionárias no Brasil em meados de 1999, como veremos, as metas não foram cumpridas em dois anos, apesar do Banco Central se mostrar determinado com o seu cumprimento praticando elevadas taxas de juros nominais e reais. 
Mesmo com os desvios da taxa de inflação de sua meta, o desempenho da economia brasileira em termos de produto tem ficado bastante aquém do desejado o que tem resultado na manutenção de elevadas taxas de desemprego. O desempenho fiscal, avaliado pela razão dívida/PIB, só começou a melhorar a partir de 2003, apesar dos superávits primários crescentes, graças à valorização cambial.

Como mencionado anteriormente, não existe um consenso exato na literatura atual sobre o melhor ou pior desempenho do produto de um país que tenha adotado oficialmente o regime de metas inflacionárias. Nesse sentido, o objetivo do artigo é qualificar o desempenho da atividade econômica e das taxas de inflação de diversos países, sejam industrializados ou em desenvolvimento, e compara-los com países que não adotaram esse tipo de regra de política monetária. Com isso será possível detectar se existe realmente uma eficiência inerente ao regime de metas inflacionárias em reduzir as taxas de inflação, e mais do que isso, se as metas tem algum impacto negativo ou positivo sobre a atividade econômica do país. Além disso, pretende-se comparar o desempenho dos países que adotaram o regime, verificando diferenças entre o grupo de países desenvolvidos e os em desenvolvimento.

Nesse sentido, serão selecionadas algumas estatísticas comuns como crescimento do produto, volatilidade do câmbio, volatilidade da inflação, entre outros que irão descrever e caracterizar o desempenho econômico dos países após a adoção do regime de metas, estas serão comparadas e por fim serão destacadas algumas características que possam justificar como o regime de metas inflacionárias pode gerar diferentes impactos na atividade econômica dos países.

Este estudo pretende contribuir com a literatura relacionada pelo fato de buscar quais as possíveis características dos países que possam justificar os efeitos distintos de uma mesma política monetária. Além disso, será discutido qual o desempenho econômico tanto de países desenvolvidos como em desenvolvimento quando da adoção do regime de metas.

O artigo está dividido em três seçôes além desta introdução e as considerações finais. A segunda seção descreve as características e definiçóes do regime de metas de inflação. A terceira seção descreve a adoção e a implementação do regime de metas inflacionárias no Brasil. A quarta seção apresenta a análise comparativa entre os países que adotaram e os respectivos 
grupos dos países, contendo tanto os que adotaram como os que náo adotaram; além disso, faz-se a comparação entre os países que adotaram, confrontando-se o desempenho do grupo de países desenvolvidos com os em desenvolvimento.

\section{O regime de metas de inflação}

Nos anos 90, alguns países da América Latina e Ásia Oriental tiveram uma experiência pouco satisfatória ao optarem por programas de estabilização baseados em âncoras cambiais. Os países emergentes ${ }^{2}$ deflagram-se em profundas crises financeiras e foram obrigados a encontrar outras alternativas de âncora nominal. Dessa forma, a estratégia de política monetária conhecida como meta inflacionária, já utilizada com sucesso em alguns países desenvolvidos como Nova Zelândia desde 1990, Canadá (1991), Reino Unido (1992) e Austrália (1994), tornou-se uma alternativa atrativa para os países emergentes. O Chile em 1991 foi o primeiro país em desenvolvimento a adotar o regime de metas como estratégia de política monetária, posteriormente outros países como a Polônia (1998), Brasil (1999), México (1999) e África do Sul (2000) seguiram essa mesma tendência.

Vários autores têm proposto um critério formal para diferenciar o regime de metas de outras estratégias de política monetária. A proposta de definição sugerida por Mishkin (2000) e Mishkin (2000) é a mais representativa na literatura. De acordo com esses autores, o regime de metas inflacionárias é uma estratégia de política monetária que concilia cinco elementos principais: (i) o anúncio ao público de uma meta numérica da inflação para um ou mais horizontes de tempo; (ii) um compromisso institucional assumindo a estabilidade de preços como o objetivo da política monetária, para o quê qualquer outro objetivo está subordinado; (iii) o uso de uma estratégia de informação em que algumas variáveis, e não apenas os agregados monetários e a taxa de câmbio, sejam utilizados como parâmetros às decisóes envolvendo os instrumentos de política; (iv) o aumento da transparência das estratégias de política monetária, por meio da comunicação ao público e aos mercados sobre os planos, objetivos e decisóes da autoridade monetária e (v) o aumento da responsabilidade do Banco Central em atingir os alvos inflacionários préestabelecidos.

${ }^{2}$ Países em transição na Europa Oriental e na antiga União Soviética foram também incluídos na categoria de mercados emergentes. 
Esses elementos evidenciam que as metas inflacionárias desempenham o papel de um arcabouço teórico ou de um marco referencial à condução da política monetária, e não apenas um conjunto de regras seguidas por autoridades monetárias.

De acordo com as idéias, originalmente, desenvolvidas na década de 30, pelos expoentes da escola de Chicago, a política monetária pode ser implementada através de regras pré-estabelecidas para todas as situaçóes conhecidas em que a economia estiver sujeita; ou de forma discricionária, decidindo-se, neste caso, a política a ser adotada em cada evento, em particular.

Nesse contexto podemos definir o regime de metas inflacionárias como uma estratégia de política monetária que parte do reconhecimento explícito de que o objetivo de longo prazo é a estabilidade de preços. Este objetivo é confirmado pelo anúncio oficial de metas quantitativas para a taxa de inflação para um ou mais períodos de tempo. Uma vez estabelecida a meta, o Banco Central tem flexibilidade para escolher a melhor combinação de instrumentos de política monetária para assim atingi-la, com base na maior disponibilidade possível de informações. Estas decisôes são anunciadas e explicitadas ao público, com o objetivo de aumentar a transparência da política monetária.

As regras do sistema de metas de inflação colocam a estabilidade de preços como objetivo principal da autoridade monetária. E como já destacado, O principal instrumento de política monetária passa a ser a taxa de juros segundo a regra de Taylor, a qual define que a taxa de juros da economia deveria ser elevada quando houvesse inflação e reduzida quando os preços estivessem em queda.

Assim, pode-se pensar a determinação da inflação por meio de uma Curva de Phillips e considerar a taxa de juros como o instrumento para controlá-la, conforme explicitado pela regra de Taylor. Assim, considerando a estrita relação entre a Curva de Phillips e a curva de oferta agregada de curto prazo da economia, sabe-se que a inflação esperada é um dos fatores que determinam a posição dessa última. Em conseqüência, o banco central pode tomar a inflação esperada - e a curva de oferta de curto prazo - como dada, e quando a oferta de moeda varia, a curva de demanda agregada se desloca e a economia move-se ao longo de uma curva de oferta agregada de curto prazo dada. Portanto, no curto prazo, uma política monetária atuante 
pode surtir efeitos inesperados sobre o produto, o desemprego, os preços e a taxa de inflação.

Contudo, essa capacidade de alterar as variáveis reais da economia mediante da criação de inflaçáo inesperada pelo banco central, somente existiria no curto prazo, segundo esta formulação. Pois, no longo prazo, o público em geral reformularia suas expectativas quanto à inflação e a curva de oferta se tornaria vertical e, conseqüentemente, a relação inversa entre inflação e desemprego também não se verificaria no longo prazo.

Essa análise pode ser resumida na seguinte expressão, dada pela Curva de Phillips:

$$
\begin{aligned}
& \pi=\pi^{\mathrm{e}}-\beta\left(\mathrm{u}-\mathrm{u}^{\mathrm{n}}\right)+\varepsilon \\
& \text { em que; } \\
& \pi \quad \text { - inflação corrente; } \\
& \pi^{\mathrm{e}} \quad \text { - inflação esperada; } \\
& \beta \quad \text { - parâmetro que indica a inclinação da curva de Phillips; } \\
& \mathrm{u} \quad \text { - taxa de desemprego; } \\
& \mathrm{u}^{\mathrm{n}} \quad \text { - taxa natural de desemprego; } \\
& \varepsilon \quad \text { - choque de oferta. }
\end{aligned}
$$

Essa equação referenciada como a Curva de Oferta de Lucas, relaciona a taxa de inflação corrente da economia à expectativa de inflação aos desvios da taxa de desemprego de sua taxa natural e a choques aleatórios de oferta. Essas variáveis são as causas da inflação no curto prazo. Entretanto, no longo prazo, as pessoas passam a esperar qualquer inflação que o Banco Central determine e a taxa de inflação corrente iguala-se à expectativa inflacionária, fazendo com que o produto (ou o desemprego) retorne a sua taxa natural. Portanto, a curva de oferta de Lucas introduz as expectativas, que supóem que os agentes tomam suas decisóes quanto à formação dos preços com base em expectativas futuras e não passadas.

Note-se que no curto prazo, dadas as expectativas, choques de oferta ou reduçóes do desemprego abaixo da taxa natural levariam a um aumento da taxa de inflação. Caso o governo tenha uma determinada meta para a taxa de 
inflação e ocorra um desvio em relação a esta, a forma de ajustar a inflação verdadeira à meta é pelo controle da demanda, o que se faria por meio da taxa de juros. Essa situação poderia ser expressa por uma regra de Taylor da seguinte forma:

$$
\mathrm{i}=\mathrm{i}^{*}+\alpha\left(\pi-\pi^{*}\right)
$$

em que:

$\mathrm{i}=$ taxa de juros

$\mathrm{i}^{*}=$ taxa de juros compatível com a taxa de desemprego

natural (estabilidade inflacionária)

$\alpha=$ parâmetro que representa o impacto de desvios

da inflação na taxa de juros

$\pi=$ taxa de inflação corrente

$\pi^{*}=$ meta de inflação

Assim, de acordo com essa expressão, sempre que a inflação está acima da meta o Banco Central deveria aumentar a taxa de juros para reduzi-la e quando ela estivesse abaixo deveria reduzir a taxa de juros.

É possível perceber que este sistema requer um amplo conhecimento do Banco Central sobre os canais de transmissão da política monetária. Como destacado nos manuais de macroeconomia e economia monetária, estes podem ser de diferentes formas: efeitos diretos sobre decisóes de investimento e consumo da sociedade, canal do crédito, preço de ativos entre outros.

De acordo com Taylor (2002), no contexto macroeconômico existem diferentes visóes a respeito dos mecanismos de transmissão monetária, como por exemplo, os preços no mercado financeiro, que demonstram o impacto das políticas monetárias sobre preços e as taxas de retorno de mercado de ativos - incluindo preços de títulos, taxa de juros e taxa de câmbio - ligando isso às decisões de gastos das empresas e famílias.

Outro canal de transmissão é o crédito. Essa visão enfatiza uma alteração nos empréstimos por bancos e intermediários financeiros como uma alternativa ao financiamento interno, em que medidas quantitativas de crédito e corporaçóes de fluxo de caixa são importantes insumos. A taxa de câmbio e a taxa de juros também são importantes mecanismos de transmissão, principalmente quando se trata de uma economia aberta e pequena, como no caso do Brasil. 
A taxa de juros em geral pode afetar a inflação por meio de dois canais de transmissão, o canal mais convencional seria que aumentos na taxa real de juros levariam a uma redução na demanda agregada, no produto e na inflação. O segundo canal seria que uma elevação na taxa real de juros provocaria uma apreciação real do câmbio, gerando um impacto negativo na taxa de inflação, direta e indiretamente, através da indução de reduçóes na demanda agregada e no produto.

Portanto, percebe-se que na ocorrência de um choque (variável aleatória na curva de Phillips), mudanças na taxa de juros trariam a inflação para a média reduzindo o componente da inflação de demanda, o que resulta em um maior controle da atividade econômica e geraçáo de desemprego.

$\mathrm{Na}$ economia brasileira, o segundo canal é considerado o mais forte, ou seja, a apreciaçáo cambial provocada por um aumento na taxa de juros da economia tem bastante efetividade em reduzir a inflação e o crescimento econômico do país (BLANCHARD, 2004).

Portanto, as consideraçóes sugerem que os elementos essenciais do regime de metas de inflação são o anúncio de uma meta numérica para a taxa de inflação juntamente com o desejo explícito do banco central e do governo em alcançar o objetivo proposto, representado, neste caso, pelo ajuste constante dos instrumentos do banco central sempre que houver sinais de que a taxa de inflação futura deva se desviar de sua meta. Além disso, o compromisso institucional do Banco Central com a meta pré-estabelecida deixa claro que quando existir algum conflito com outros objetivos da política macroeconômica, como, por exemplo, o crescimento do produto real, queda no desemprego, a estabilidade financeira, o equilíbrio do balanço de pagamentos, entre outros, a estabilidade dos preços deve ser tratada de forma prioritária.

O sucesso do regime de metas de inflação em reduzir a variabilidade da inflação dos países está relacionado com alguns pontos que merecem destaque. A credibilidade atribuída ao comprometimento das autoridades monetárias com a estabilidade de preços é um fator que pode ter algum impacto sobre a conversão das taxas de inflação para as metas estabelecidas previamente.

Os países desenvolvidos têm maior facilidade em construir uma forte credibilidade em relação ao seu comprometimento com a estabilidade de preços, portanto, estes países tendem a apresentar menores desvios das taxas 
de inflação efetiva em relação à meta. Já os países em desenvolvimento enfrentam maior dificuldade em construir um grau elevado de credibilidade, elevando o custo da convergência das taxas de inflação para a sociedade desses países, que terão que conviver com uma política monetária mais agressiva, ou seja, com a prática de elevação nas taxas de juros por parte de seus Bancos Centrais na tentativa incerta de atingir as metas de inflação prédeterminadas.

Outro ponto que pode dificultar a convergência das taxas de inflação para as metas é a dominância fiscal e financeira dos países. Os países que estão mais propensos a enfrentar esse tipo de dominância são aqueles que apresentam um fraco regime fiscal, ineficiências no sistema financeiro, elevada volatilidade cambial e conseqüentemente maior propensão a serem contaminados por choques externos. Freqüentemente, os países que apresentam tais características enfrentam maiores dificuldades e custos no processo de convergência das taxas de inflação para as metas determinadas. Outro aspecto a ser considerado é a existência de inércia inflacionária associada a presença de contratos ou mecanismos de revisão de valores que fazem com que choques inflacionários se propaguem no tempo. Exemplos deste fato são os contratos de concessão com clausulas de correção e a existência de políticas salariais que buscam a recomposição dos picos salariais.

A rigidez atribuída ao sistema de metas inflacionárias pelos países também pode ter um efeito perverso sobre os custos relativos à convergência das taxas de inflação para a meta. Quanto maior a rigidez com que o regime é implementado, maior a volatilidade das taxas de juros e do produto, elevando os custos para a sociedade do cumprimento das metas previamente estabelecidas.

Portanto, algumas dificuldades podem ser encontradas no processo de convergência das taxas de inflação da economia para as taxas estabelecidas pelas autoridades monetárias responsáveis pelo sistema de metas inflacionárias. A credibilidade atribuída à própria autoridade monetária, a propensão dos países à dominância fiscal e financeira e a rigidez na implementação do regime de metas podem dificultar, ou elevar o custo da convergência das taxas de inflaçáo dos países para as metas. 


\section{A adoção do regime de metas inflacionárias no Brasil: resultados alcançados}

Mesmo com o comprometimento institucional do Banco Central com a estabilidade de preços dos países que adotam o regime de metas inflacionárias, a implementação do regime pode se dar de forma mais flexível em relação à sua definição formal. Dessa forma, a constatação do efeito negativo sobre a atividade econômica quando associado à presença de choques faz com que os sistemas de metas de inflação entre os países se diferenciem em relação ao modo de implementação e flexibilidade do regime. Diante disso, as autoridades monetárias podem definir diferentes desenhos para alcançar o objetivo de estabilidade de preços na escolha do índice que baliza as metas, podendo ser um índice cheio ou baseado em preços menos voláteis (core ou núcleo da inflação), na definição do intervalo de tolerância ou no prazo para atingir a meta de inflação estipulada.

O Canadá, por exemplo, é um caso clássico de utilização bem sucedida do núcleo de inflação como medida do índice de preços ao consumidor, referenciado pela meta de inflação. Com o objetivo de remover efeitos transitórios e obter um melhor ajuste à trajetória de longo prazo de inflação, o regime de metas desse país está balizado, desde sua implementação, em uma medida do núcleo de inflação: o Core CPI. Como observado por Mishkin e Posen (1997), o regime de metas de inflação canadense é completamente flexível, de modo que na condução da política monetária, o crescimento e as flutuaçóes do produto real são bastante relevantes.

Outra forma de flexibilização do regime de metas é a definição do horizonte de tempo para que a meta seja cumprida. Na Austrália, o horizonte de tempo utilizado para averiguar o cumprimento da meta não está prédeterminado, ou seja, as metas devem ser alcançadas em média, ao longo do tempo. Como citado por Petrassi e Ferreira (2002), uma característica-chave do regime australiano é a flexibilidade da política monetária, principalmente devido ao horizonte de tempo relevante à avaliação do sistema de metas de inflação para atingir seus objetivos. Com a finalidade de se adotar uma política mais flexível é necessário que a credibilidade dos formuladores de política econômica do país seja elevada. Tendo isto se concretizado, a instituição de horizonte de tempo mais longo pode ser uma forma alternativa de enfrentar choques adversos e, ao mesmo tempo, não comprometer a credibilidade do regime. 
No Brasil o regime original previa uma elevada rigidez em relação ao cumprimento das metas, com a definição de uma meta numérica para cada ano com um intervalo de tolerância de dois pontos percentuais para cima ou para baixo, e com o intuito de aumentar a transparência e credibilidade do regime, também foi estabelecido que na impossibilidade de se atingir a meta estabelecida, o presidente do banco central deve publicar uma carta aberta contendo os fatos pelos quais a convergência da taxa de inflação à meta não foi concretizada e as principais medidas cabíveis para que a convergência se efetue, bem como o tempo necessário para tanto.

Como visto, o sistema de metas inflacionárias implementado no Brasil inicialmente não era muito flexível. Entretanto, ao longo do tempo houve algumas alteraçóes, evidenciando a proximidade com um regime mais flexível que admite a incoerência de perseguir metas inatingíveis dada a realidade macroeconômica do país. Um primeiro passo nesse sentido foi dado ao final de 2002, quando houve uma modificação no cálculo da meta a ser perseguida pelo Banco Central do Brasil. Atualmente o COPOM (Comitê de Política Monetária) trabalha com o conceito de meta ajustada, em que, à meta preestabelecida pelo CMN (Conselho Monetário Nacional), adicionam-se os impactos inerciais da inflaçáo do ano anterior e o efeito primário dos choques de preços administrados por contrato e os preços monitorados.

Posteriormente, em 2003 ocorreu a introdução de um intervalo de tolerância maior para as metas, passando de 2 para 2,5\% para cima ou para baixo. $\mathrm{O}$ objetivo de tais mudanças no sistema tem como fundamento uma prática comum entre os bancos centrais quando confrontados com choques de oferta de grande magnitude, isto é, diluir a convergência da taxa de inflação corrente às metas em um período mais longo, evitando custos de ajustamentos graves para a economia (MEIRELLES, 2003). 
Desde a implementação do regime de metas inflacionárias tivemos o seguinte desempenho em termos de taxas inflação:

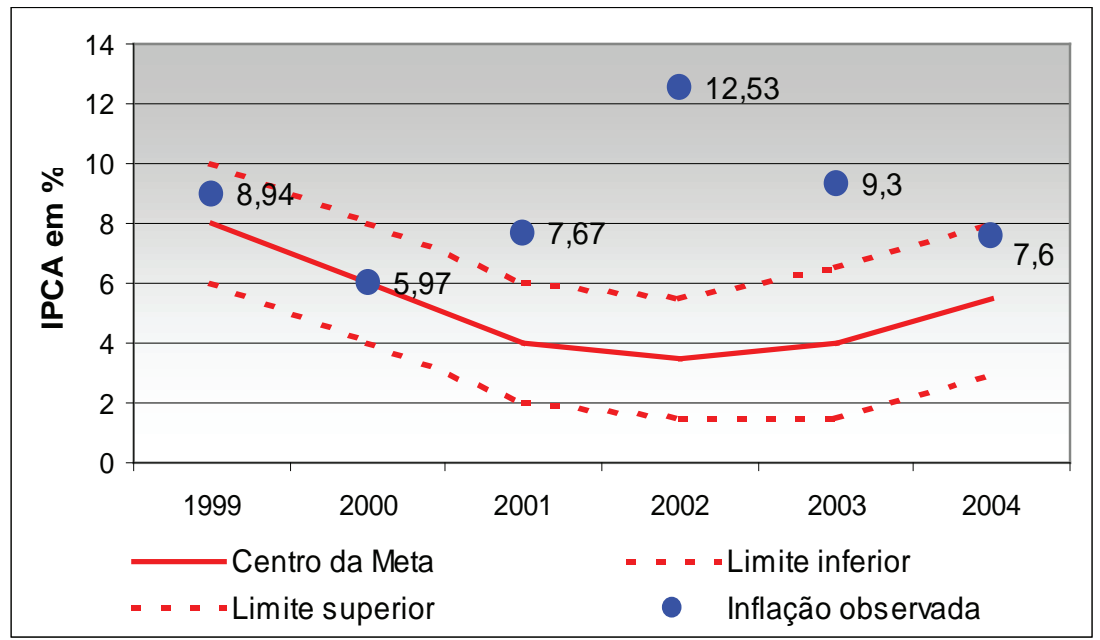

Gráfico 1 - O regime de metas de inflação no Brasil

FONTE: Banco Central do Brasil

A partir do gráfico 1, pode-se notar o não cumprimento da meta nos anos de 2001, 2002 e 2003. Tal fato está relacionado aos choques ocorridos na economia como a crise de energia, atentados terroristas no exterior, crise financeira da Argentina, crises cambiais, aumento do risco- país e repasses cambiais. Em 2004 a variação do IPCA ficou dentro do intervalo de tolerância da meta estabelecida para o ano, atingindo um valor de 7,6\%.

Para 2005, a meta de inflação definida foi de 5,1\% com intervelo de tolerância de 2,5 pontos percentuais para cima ou para baixo, e em 2006 a meta estabelecida pelo CMN é de 4,5\%.

Entretanto, mesmo não cumprindo a meta em vários anos, o Brasil apresentou um baixo crescimento econômico com uma taxa média da ordem de $2 \%$ ao ano no período, e manteve uma elevada taxa de desemprego que ficou na faixa dos $12 \%$, um patamar muito elevado para um país marcado por profundas discrepâncias como o Brasil. A tabela a seguir mostra os principais indicadores econômicos brasileiros desde 1999, pode-se notar o 
baixo crescimento econômico, elevado desemprego e o crescimento da dívida pública frente à relativa estabilidade inflacionária.

Tabela 1 - Brasil: indicadores econômicos - 1999-2004

\begin{tabular}{|l|c|c|c|c|c|c|c|}
\cline { 2 - 9 } \multicolumn{1}{c|}{} & $\mathbf{1 9 9 9}$ & $\mathbf{2 0 0 0}$ & $\mathbf{2 0 0 1}$ & $\mathbf{2 0 0 2}$ & $\mathbf{2 0 0 3}$ & $\mathbf{2 0 0 4}$ & Média \\
\hline Crescimento do PIB (\%) & 0,8 & 4,4 & 1,4 & 1,5 & $-0,22$ & 5,2 & 2,18 \\
\hline Preços & & & & & & & \\
\hline Índice de Preços ao Cons. Amplo IBGE & 8,94 & 5,97 & 7,7 & 12,5 & 9,3 & 7,6 & 8,6 \\
\hline Índice de Preços ao Consumidor - Fipe & 8,3 & 4,38 & 7,1 & 9,9 & 8,17 & 6,5 & 7,4 \\
\hline Índice de Preços ao Atacado - DI & 28,9 & 12,06 & 11,8 & 35,41 & 6,27 & 14,6 & 18,2 \\
\hline Setor Público - NFSP (\% do PIB) & & & & & & & \\
\hline Operacional* & 3,41 & 1,17 & 1,4 & $-0,01$ & 0,88 & $-2,07$ & 0,79 \\
\hline Primário* & $-3,23$ & $-3,47$ & $-3,64$ & $-3,89$ & $-4,25$ & $-4,61$ & $-3,85$ \\
\hline Dívida Líquida Total (\% do PIB)** & 49,4 & 49,4 & 52,6 & 55,5 & 57,2 & 51,9 & 52,6 \\
\hline Política Monetária & & & & & & & \\
\hline Taxa de juros Selic (\%)*** & 24,3 & 17,6 & 17,5 & 19,2 & 23,5 & 16,4 & 20,1 \\
\hline Emprego & & & & & & & \\
\hline Taxa de desemprego ref. 30 dias (IBGE - \%)*** & 12,1 & 11,0 & 11,2 & 11,7 & 12,3 & 11,4 & 11,6 \\
\hline
\end{tabular}

FONTE: IBGE, Ipeadata e Banco Central do Brasil

* Com desvalorizaçáo cambial.

** Dado do último mês do ano.

*** Média mensal.

A seção seguinte demonstrará algumas estatísticas de países desenvolvidos e emergentes que adotam ou não o sistema de metas de inflação para posteriormente serem comparadas e com isso detectar a eficiência do regime em reduzir as taxas médias de inflação e melhorar o desempenho da atividade econômica. 


\section{Comparação do desempenho econômico de países que adotam e dos que não adotam o regime de metas de inflação}

Após a implementação do regime de metas de inflação na Nova Zelândia em 1990, muitos países desenvolvidos e em desenvolvimento adotaram esse regime como estratégia de política monetária com o objetivo de garantir a estabilidade de preços.

Muitos estudos já foram realizados para comparar o regime de metas de inflação com outras estratégias que objetivam a estabilidade de preços. Alguns estudos não foram conclusivos e não comprovaram a superioridade do regime de metas inflacionárias como o de Neumann e Hagen (2002), outros como o estudo já mencionado de Wu (2004) comprovou empiricamente que a adoçáo do regime de metas de inflação e a sua credibilidade perante a população são eficazes em reduzir as taxas de inflação dos países.

Um dos objetivos desse trabalho é analisar qualitativamente se o regime de metas de inflação é eficaz em garantir a estabilidade de preços. Para isso será necessário comparar dados relativos às taxas de inflação em um determinado período de países que adotam e que não adotam o regime. A data de adoção do regime entre os países varia entre 1990 (Nova Zelândia) e 2001 (Islândia). 
A tabela a seguir apresenta os países que adotaram oficialmente o regime de metas inflacionárias.

Tabela 2 - Metas de inflação: países que adotam

\begin{tabular}{|c|c|}
\hline Países desenvolvidos & Ano de adoçáo \\
\hline Austrália & 1994 \\
\hline Canadá & 1991 \\
\hline Islândia & 2001 \\
\hline Nova Zelândia & 1990 \\
\hline Noruega & 2001 \\
\hline Reino Unido & 1992 \\
\hline Suécia & 1993 \\
\hline Suíça & 2000 \\
\hline Países em desenvolvimento & Ano de adoçáo \\
\hline África do Sul & 2000 \\
\hline Brasil & 1999 \\
\hline Chile & 1991 \\
\hline Colômbia & 1999 \\
\hline Coréia do Sul & 1998 \\
\hline Czech Republic & 1998 \\
\hline Hungria & 2001 \\
\hline Israel & 1992 \\
\hline México & 1999 \\
\hline Peru & 1994 \\
\hline Polônia & 1998 \\
\hline Tailândia & 2000 \\
\hline
\end{tabular}

Considerando o fato de que os países adotaram o regime de metas de inflação em diferentes períodos e ambiente macroeconômico, vamos considerar um período de tempo fixo para a realização das análises das estatísticas descritivas dos países. A amostra de dados considerada será referente aos anos entre 1996 e 2004, compreendendo um período em que alguns países já haviam adotado o regime há algum tempo e outros em que a adoção se deu no decorrer desses anos. 
A tabela a seguir mostra os dados relativos a volatilidade da taxa de inflação, crescimento do produto, taxa de câmbio, taxa de juros e desemprego de países desenvolvidos e em desenvolvimento que adotam oficialmente o sistema de metas de inflação.

Tabela 3 - Volatilidade das variáveis - período: 1996-2004

\begin{tabular}{|c|c|c|c|c|c|}
\hline Países & Inflação & $\begin{array}{l}\text { Crescimento } \\
\text { Real PIB }\end{array}$ & $\begin{array}{c}\text { Taxa de } \\
\text { Câmbio* }\end{array}$ & $\begin{array}{c}\text { Taxa de } \\
\text { Juros }\end{array}$ & $\begin{array}{c}\text { Taxa de } \\
\text { Desemprego }\end{array}$ \\
\hline Desenvolvidos ** & 0,93 & 0,95 & - & - & 0,44 \\
\hline Austrália & 0,52 & 0,80 & 0,14 & 0,90 & 0,92 \\
\hline Canadá & 1,08 & 1,45 & 0,06 & 1,11 & 0,93 \\
\hline Nova Zelândia & 0,39 & 1,44 & 0,18 & 1,39 & 0,97 \\
\hline Suécia & 0,88 & 1,32 & 0,14 & 0,91 & 1,53 \\
\hline Suíça & 0,38 & 1,31 & 0,11 & 0,93 & 0,98 \\
\hline Reino Unido & 0,66 & 0,66 & 0,07 & 1,13 & 1,10 \\
\hline $\begin{array}{l}\text { Países desenvolvidos } \\
\text { que adotam metas }\end{array}$ & 0,65 & 1,16 & 0,12 & 1,06 & 1,07 \\
\hline $\begin{array}{c}\text { Países em } \\
\text { desenvolvimento }\end{array}$ & 7,83 & 1,18 & - & - & 2,6 \\
\hline Brasil & 4,23 & 1,88 & 0,41 & 4,00 & 1,11 \\
\hline Chile & 1,94 & 2,42 & 0,20 & nd & 1,30 \\
\hline Colômbia & 5,82 & 2,50 & 0,34 & nd & 4,18 \\
\hline Israel & 4,03 & 2,75 & 0,13 & 0,51 & 1,40 \\
\hline México & 9,98 & 2,54 & 0,13 & 8,94 & 0,81 \\
\hline Peru & 3,63 & 2,41 & 0,13 & nd & $\mathrm{Nd}$ \\
\hline Polônia & 6,36 & 1,98 & 0,14 & 3,35 & 3,38 \\
\hline $\begin{array}{c}\text { Países em } \\
\text { desenvolvimento que } \\
\text { adotam metas }\end{array}$ & 5,14 & 2,35 & 0,21 & 4,19 & 2,03 \\
\hline
\end{tabular}

FONTE: FMI, International Financial Statistics.

* Desvio padrão / média

** Inclui todos os países considerados desenvolvidos e em desenvolvimento de acordo com a classificação do Fundo Monetário Internacional.

nd: dado não disponível 
Para comparar os dados de volatilidade dos países que adotam o sistema de metas de inflação em relação aos países que não adotam vamos observar os dados agregados relativos as variáveis selecionadas de todos os países desenvolvidos e em desenvolvimentos.

A volatilidade da taxa de inflação dos países desenvolvidos que adotam oficialmente o regime de metas inflacionárias se mostrou inferior a volatilidade do grupo dos países desenvolvidos em geral. Dessa forma, podemos constatar que em economias mais desenvolvidas o regime de metas de inflação tem contribuído para uma maior estabilidade de preços, diminuindo a variabilidade das taxas de inflaçáo dos países.

No grupo dos países em desenvolvimento a volatilidade das taxas de inflação dos países que adotam o regime de metas inflacionárias também se mostrou inferior a volatilidade média de todos os países que fazem parte do grupo.

Em relação ao desempenho da atividade econômica dos países, podemos observar uma maior variabilidade do crescimento real do produto de todos os países, desenvolvidos e em desenvolvimento, que adotam o sistema de metas de inflação em relação aos países que não adotam.

A elevada variabilidade das taxas de crescimento do produto dos países que adotam o regime de metas inflacionárias pode ser explicada pela própria característica inerente a esse tipo de estratégia de política monetária. A estabilidade de preços é o principal objetivo em uma economia que adota o sistema de metas, colocando em segundo plano todas as outras questóes referentes ao desempenho macroeconômico dos países. Portanto, a condução de uma política monetária mais agressiva para garantir a estabilidade de preços e o cumprimento das metas de inflação determinada pelas autoridades monetárias pode gerar efeitos negativos sobre o produto da economia, elevando a volatilidade do seu crescimento real.

A volatilidade da taxa de desemprego do grupo dos países avançados se mostrou inferior a dos países desenvolvidos que adotam o sistema de metas inflacionárias, demonstrando que a adoção de uma regra de política monetária que tem o objetivo principal de garantir a estabilidade de preços da economia pode contribuir para uma elevação na taxa de desemprego do país, como conseqüência de uma política monetária mais agressiva que gera efeitos negativos sobre a atividade econômica. 
Entre os países em desenvolvimento, houve uma pequena diferença entre os países que adotam e os que não adotam o regime de metas inflacionárias em relação à volatilidade da taxa de desemprego, os primeiros apresentaram uma volatilidade da taxa de desemprego menor do que a volatilidade de todos os países que fazem parte do grupo das economias em desenvolvimento.

Portanto, de acordo com as estatísticas descritivas dos países que adotam o sistema de metas inflacionárias e as informaçóes sobre o comportamento das variáveis agregadas para um grupo de países, podemos constatar que tanto para os países desenvolvidos como para os países em desenvolvimento a adoção do sistema de metas inflacionárias reduziu a variabilidade das taxas de inflação, comprovando a eficácia do regime em garantir a estabilidade de preços. Além disso, podemos afirmar que os países que adotam o sistema de metas de inflação geralmente têm uma maior variabilidade do crescimento real do produto e das taxas de desemprego.

A tabela a seguir mostra a média da taxa de crescimento real e da taxa de inflação dos países que adotam o sistema de metas inflacionárias assim como as estatísticas para o grupo dos países em desenvolvimento e desenvolvidos. 
Tabela 4 - Médias das taxas de inflaçáo e crescimento do produto

(\%) - período: 1996-2004

\begin{tabular}{|l|c|c|}
\hline \multicolumn{1}{|c|}{ Países } & Taxa de inflaçáo & Cresc. Real PIB \\
\hline Desenvolvidos & $\mathbf{1 , 8 7}$ & $\mathbf{2 , 7 7}$ \\
\hline Austrália & 2,53 & 3,76 \\
\hline Canadá & 2,00 & 3,41 \\
\hline Nova Zelândia & 2,11 & 3,13 \\
\hline Suécia & 1,50 & 2,64 \\
\hline Suíça & 0,73 & 1,41 \\
\hline Reino Unido & 1,51 & 2,86 \\
\hline Países desenvolvidos que adotam & $\mathbf{1 , 7 3}$ & $\mathbf{2 , 8 7}$ \\
\hline Países em desenvolvimento & $\mathbf{9 , 3}$ & $\mathbf{5 , 0 3}$ \\
\hline Brasil & 7,61 & 2,17 \\
\hline Chile & 3,97 & 3,86 \\
\hline Colômbia & 11,72 & 1,72 \\
\hline Israel & 4,36 & 2,84 \\
\hline México & 13,03 & 3,68 \\
\hline Peru & 4,34 & 2,91 \\
\hline Polônia & 8,43 & 4,19 \\
\hline Países em desenvolvimento que adotam & $\mathbf{7 , 6 4}$ & $\mathbf{3 , 0 5}$ \\
\hline
\end{tabular}

FONTE: FMI, International Financial Statistics

De acordo com a tabela 4, podemos observar que a média das taxas de inflação dos países desenvolvidos que adotam o sistema de metas inflacionárias é ligeiramente inferior a média do grupo dos países desenvolvidos. Portanto na média, a adoção do sistema de metas reduz as taxas de inflação dos países.

No caso dos países em desenvolvimento, isso também ocorre, ou seja, em média a taxa de inflação das economias emergentes que adotam o regime de metas de inflação é inferior a média de inflação dos países que não adotam esse regime. Dessa forma, mais uma evidência estatística de que o sistema de metas inflacionárias é eficaz em reduzir as taxas médias de inflação dos países.

Em relação ao crescimento do produto, apesar da sua maior volatilidade 
em ambos os grupos de países, desenvolvidos e em desenvolvimento, em relação aos países que não adotam o regime de metas inflacionárias, para as economias desenvolvidas que adotam o regime a média da taxa de crescimento real do produto é bastante próxima à média do grupo dos países desenvolvidos. Já entre os países em desenvolvimento, os países que adotam o regime de metas inflacionárias experimentam uma taxa de crescimento média bastante inferior ao grupo de todos os países em desenvolvimento, sinalizando que a adoção deste regime para este grupo de países pode afetar negativamente o crescimento.

Dessa forma, pode-se notar que entre os países que adotam o regime de metas inflacionárias, os países desenvolvidos vêm apresentando um melhor desempenho em relação aos países em desenvolvimento.

De acordo com a tabela 3 podemos observar que os países em desenvolvimento que adotam o sistema de metas de inflação apresentam uma elevada volatilidade da taxa de câmbio em relação aos países desenvolvidos que adotam o mesmo tipo de regra monetária. Além disso, a volatilidade da taxa de juros dos países em desenvolvimento também é significativamente alta em relação aos países desenvolvidos. Portanto, a adoção do regime de metas de inflação pelos países em desenvolvimento provoca uma maior variabilidade do crescimento real do produto, que pode estar relacionado com vulnerabilidade da economia dos países emergentes, ou seja, estes estáo mais propensos a enfrentar o trade-off de curto prazo entre estabilidade das taxas de inflação e crescimento do produto.

É importante destacar que a média de crescimento dos países desenvolvidos que adotam o regime de metas inflacionárias é bastante próxima à taxa média de crescimento dos países que não adotam o regime, e as taxas médias de inflação dos países que adotam o regime também se mostram inferiores às taxas dos países que não adotam. Portanto o custo de manutenção do regime de metas inflacionárias em países desenvolvidos não é elevado, já que o desempenho da inflação é melhor (inflação média 7\% mais baixa em relação ao grupo dos desenvolvidos) e as taxas médias de crescimento não são significativamente diferentes das taxas médias encontradas para o grupo de todos os países desenvolvidos.

Os países em desenvolvimento que adotam o regime de metas inflacionárias enfrentam uma situação distinta dos países desenvolvidos, pois o regime garante uma taxa média de inflação $17 \%$ mais baixa do que a taxa média de 
inflação do grupo dos países em desenvolvimento, entretanto a redução da taxa média de crescimento do produto é de 39\% em relação à taxa média de crescimento do produto para o grupo.

Portanto, os países em desenvolvimento que adotam o sistema de metas de inflação enfrentam maiores custos no processo de conversão da taxa de inflação para a meta, enquanto que os países desenvolvidos não se submetem a taxas médias de crescimento do produto muito inferior a taxa média de crescimento de todos os países desenvolvidos e ainda conseguem alcançar a estabilidade de preços almejada pelo sistema de metas inflacionárias adotado.

A justificativa para o fato dos países em desenvolvimento apresentarem um custo maior em termos de variabilidade e média das taxas de crescimento do produto quando da adoção do sistema de metas inflacionárias, pode ser dada pela maior propensão desses países em enfrentar dificuldades na construção de credibilidade das autoridades monetárias em relação à manutenção de estabilidade de preços. Além disso, os países emergentes estão mais propensos a ocorrência da dominância fiscal, financeira e contaminação de choques externos, dificultando a ação dos bancos centrais em realizarem uma política monetária eficaz na manutenção de baixas taxas de inflação e pequenas variaçóes no crescimento do produto da economia.

\section{Considerações finais}

Entre as estratégias de políticas monetárias existentes, o regime de metas de inflação apresenta-se como o de maior apelo na atualidade. Grande parte dos países desenvolvidos e em desenvolvimento têm adotado essa estratégia com o objetivo de aliar estabilidade de preços ao crescimento do produto e do emprego.

Atualmente, em torno de 20 países entre desenvolvidos e em desenvolvimento adotaram oficialmente o sistema de metas inflacionárias, estes têm apresentado menor volatilidade das taxas de inflação ao custo de maiores variabilidades nas taxas de crescimento real do produto de suas economias. Essa reduçáo no crescimento médio do produto dos países que adotaram o sistema de metas inflacionárias está relacionada à realização de políticas monetárias mais agressivas por parte das autoridades monetárias dos países que se vêem comprometidas com a estabilidade de preços. 
A adoção do regime de metas inflacionárias por um país requer que as autoridades monetárias destes tenham a estabilidade de preços e o cumprimento das metas de inflação como objetivo principal na conduçáo da política monetária, subordinando todas as outras questóes macroeconômicas a um objetivo secundário, inclusive as taxas de crescimento do produto do país.

Portanto, a adoção do regime de metas inflacionárias requer a utilização de instrumentos de política monetária que garantam a estabilidade de preços da economia, dando espaço para a realização de políticas monetárias agressivas, com elevadas taxas de juros que acabam prejudicando a atividade econômica do país. De fato, de acordo com as estatísticas apresentadas nesse trabalho, a volatilidade das taxas de inflação dos países que adotam o regime de metas inflacionárias é inferior a dos países que não adotam o regime, entretanto a volatilidade das taxas de crescimento do produto é alta em relação aos países que não adotam.

Esse resultado é encontrado tanto para países desenvolvidos como para os países em desenvolvimento, entretanto esses últimos enfrentam um custo mais elevado em relação à variabilidade e média das taxas de crescimento do produto de suas economias quando da adoção do regime de metas de inflação.

Algumas dificuldades podem ser encontradas no processo de convergência das taxas de inflação da economia para as taxas estabelecidas pelas autoridades monetárias responsáveis pelo sistema de metas inflacionárias. A credibilidade atribuída à própria autoridade monetária, a propensão dos países à dominância fiscal e financeira e a rigidez na implementação do regime de metas podem dificultar, ou elevar o custo da convergência das taxas de inflação dos países para as metas.

Esse elevado custo no processo de convergência das taxas de inflação para a meta está presente principalmente no desempenho dos países em desenvolvimento, estes são mais propensos à dominância fiscal, financeira, contaminaçóes de crises externas e baixa credibilidade das autoridades monetárias em relação ao comprometimento das mesmas com a estabilidade de preços, o que pode justificar o pior desempenho dos países em desenvolvimento em relação aos países desenvolvidos quando da adoção do regime de metas de inflação.

O Brasil, assim como todos os países em desenvolvimento que adotam 
o sistema de metas inflacionárias, vem apresentando baixa volatilidade das taxas de inflação e baixo crescimento do produto em relação à média dos países em desenvolvimento, além disso seu desempenho em relação aos países desenvolvidos é bastante inferior.

Pesquisas quantitativas podem ser realizadas para quantificar o custo de adoção do regime de metas inflacionárias nos países em desenvolvimento como o Brasil, dessa forma este se constitui objetivo de pesquisas futuras.

\section{Referências Bibliográficas}

ARESTIS, Philip; SAWYER, Malcolm. Inflation targeting: a critical appraisal. Working Paper, N.Y., Annandale-on-Hudson, The Levy Economics Institute, n. 388, 2003. Disponível em: http://econwpa.wustl.edu/eprints/ mac/papers/0309/0309015.abs. Acesso em: 08 de junho de 2005.

BLANCHARD, Olivier. Fiscal dominance and inflation targeting: lessons from Brazil. Working Paper, Cambridge, NBER, n. 10389, 2004.

MEIRELLES, Henrique de Campos. Carta Aberta, 21 de janeiro de 2003, para o Ministro da Fazenda, Antônio Palocci Filho enviada pelo Presidente do Banco Central do Brasil. Disponível em: http//: www.bcb.gov.b. Acesso em: 25 de setembro de 2004.

MISHKIN, Frederic. S. Inflation targeting in emerging-market countries. The American Economic Review, v. 90, n. 2, p. 105-109, 2000.

MISHKIN, Frederic S.; POSEN, Adam Simon. Inflation targeting: lesson from four countries. Working Paper, Cambridge, National Bureau of Economic Research, n. 6126, 1997. Disponível em: http://www.nber.org/papers. Acesso em: 15 de abril de 2003.

NEUMANN, Manfred J. M.; HAGEN, Jürgen von. Does inflation targeting matter? Federal Reserve Bank of St. Louis Review, v. 84, n. 4, p. 149-153, 2002.

PETRASSI, Myrian Beatriz Silva; FERREIRA, Thaís Porto. Regime de metas para a inflação: resenha sobre a experiência internacional. Notas Técnicas do Banco Central do Brasil, n. 30, nov. 2002. Disponível em: http://www. bacen.gov.br. Acesso em: 22 de junho de 2003. 
TAYLOR, John. The monetary transmission mechanism and the evaluation of the monetary policy rules. USA-Stanford: Stanford University, Treasury Departmant, 2002.

WU, Thomas Yen Hon. Does inflation targeting reduce inflation? An analysis for the OECD industrial countries. Working Paper Series, Banco Central do Brasil, n. 83, 2004. Disponível em: http://www.bcb.gov.br/publicaçôes. Acesso em: 20 de janeiro de 2005. 